\title{
A PROSPECTIVE OBSERVATIONAL STUDY ON MEDICATION USE PATTERN IN PATIENTS WITH RISK FACTORS OF CHRONIC KIDNEY DISEASE
}

\author{
AVEZ ALI ${ }^{1 *}$, PAWAN KUMAR ${ }^{2}$, JAVED AKHTAR ANSARI ${ }^{3}$, MEENAZ FATIMA ${ }^{4}$, FIRDOUS IRRUM ${ }^{4}$ \\ ${ }^{1}$ Department of Pharmaceutical Sciences, Singhania University, Jhunjhunu, Rajasthan, India. ${ }^{2}$ Department of Pharmaceutical Sciences, \\ School of Pharmacy and Medicine, Singhania University, Jhunjhunu, Rajasthan, India. ${ }^{3}$ Department of Pharmacology, Mesco College \\ of Pharmacy, Hyderabad, Telangana, India. ${ }^{4}$ Department of Pharmacy Practice, Shadan College of Pharmacy, Hyderabad, India. Email: \\ owais4peace@gmail.com
}

Received: 05 October 2021, Revised and Accepted: 11 November 2021

\section{ABSTRACT}

Objectives: The current study was undertaken to review and assess the medication usage pattern in patients with chronic kidney disease (CKD).

Methods: A 12-month prospective observational study was carried out at Shadan Teaching and General Hospital, Peerancheru (Hyderabad), involving 384 CKD patients considering the inclusion and exclusion criteria. Medication evaluation for optimization was done using the World Health Organization (WHO) core prescribing indicators. Data collected were entered using Microsoft Excel. Descriptive statistics such as mean, percentage, and standard deviation (SD) were used to present sociodemographic characteristics of the study participants.

Results: Out of the total of 384 patients, 249 (65\%) were male and 135 (35\%) were female with a mean age of 58.28 (SD: 13.12 ). A total of 384 prescriptions were scrutinized with a total of 3634 drugs, out of which drugs acting on the cardiovascular system were the most prescribed drugs (36.37\%). The average number of drugs per prescription was found to be 9.08 considering the total number of prescriptions. The percentage of drugs prescribed by generic name was $15.57 \%$. The percentage of encounters with antibiotics was $25 \%$, whereas the percentage of encounters with injections was $86 \%$. The percentage of drugs prescribed from the Essential Drug List or Formulary was found to be $26.36 \%$.

Conclusion: Assessment of medication usage patterns using the WHO core indicators in CKD patients helps to reinforce the current hospital guidelines for the optimal usage of medications. The introduction of a clinical pharmacist along with a multidisciplinary team provides intensive care to the patients and helps to improve the clinical outcome.

Keywords: Chronic kidney disease, Medication usage pattern, Long-term treatment, Medication-related problems, World Health Organization prescribing indicators.

(C) 2021 The Authors. Published by Innovare Academic Sciences Pvt Ltd. This is an open access article under the CC BY license (http://creativecommons.org/ licenses/by/4.0/) DOI: http://dx.doi.org/10.22159/ajpcr.2021v14i12.43513. Journal homepage: https://innovareacademics.in/journals/index.php/ajpcr

\section{INTRODUCTION}

The kidneys are organs that serve a number of essential regulatory roles. Most of us know that our kidneys function as filters, removing metabolic wastes and toxins from the blood and excreting them through the urine. But the kidneys also serve other essential functions. Through various regulatory mechanisms, the kidneys help maintain the body's water balance, electrolyte balance, and acid-base balance. Additionally, the kidneys produce or activate hormones that are involved in erythrogenesis, calcium metabolism, and the regulation of blood pressure and blood flow [1].

Due to the rise in the prevalence and incidence of chronic kidney disease (CKD), there is a major threat among the general population. It remains a mainstay problem throughout the world. Nearly $11-13 \%$ of CKD cases remain prevalent globally. As per the World Health Organization (WHO), the annual death rate of 850,000 contributed by this ailment [2].

Renal failure is a broad term mainly associated with the incompetency of kidneys to carry out their normal homeostatic and excretory function results in the accumulation of nitrogenous waste products in the body. It could be acute or chronic. CKD is characterized by the progressive morphological and physiological detrimental changes in the kidneys persistent for more than 3 months which is usually irreversible. Serum creatinine levels remain elevated for more than 3 months and estimated glomerular filtration rate is estimated to be $<60 \mathrm{ml} / \mathrm{min} / \mathrm{m}^{2}$ [3].

Medication usage pattern in CKD patient varies from patient to patient depending on the condition and duration of the chronicity. Hence, it is essential to analyze the medication usage pattern among CKD patients from time to time as they need to acquire the medications throughout their life. In India, CKD remains a major threat to the health-care system as well as the patient's well-being. Conducting the drug utilization survey for chronic diseases helps to promote rational use of drugs [2].

In 2017, the total mortality rate because of CKD and cardiovascular disease attributed to impaired kidney function was estimated to be $4.6 \%$. The overall mortality rate raised by $41.5 \%$ from 1990 to 2017 . Researchers also reported that diabetic kidney disease remains the apparent cause of CKD [4]. Since very limited studies are available in India on the prescribing trends among CKD patients, this study was carried out with the main focus on the medication usage pattern in the management of CKD patients and also to assess the prescription following the rational use.

\section{METHODS}

\section{Study site}

The study was conducted at Shadan Institute of Medical Sciences, Peerancheru, Hyderabad.

\section{Study design}

- Prospective observational study

- Review and collection of cases.

Study duration

The study was carried out for 12 months. 
Sample size

Approximately 384 patients were enrolled in the study who fulfilled the inclusion and exclusion criteria.

\section{Inclusion criteria}

The following criteria were included in the study:

1. All CKD patients

2. Both male and female patients

3. Patients with/without comorbid conditions

4. Patients with risk factors of CKD.

\section{Exclusion criteria}

The following criteria were excluded from the study:

1. Patients refused to participate in the study

2. Patients Who cognitive impairment

3. Pregnant and lactating women.

\section{Research methodology}

Medication evaluation for optimization was done using the WHO core prescribing indicators, that is,

- Average number of drugs per encounter

- Percentage of drugs prescribed by generic name

- Percentage of encounters with an antibiotic prescribed

- Percentage of encounters with an injection prescribed

- Percentage of drugs prescribed from the essential medicine list or formulary.

Study approval

Permission for collecting patient data was approved by the ethical committee of Shadan Hospital. It also permits the utilization of the hospital facilities for regular follow-ups of prescriptions for research work.

\section{Statistical analysis}

Data were checked for completeness, correctness, and grouped accordingly. Data collected were entered using Microsoft Excel. Descriptive statistics such as mean, percentage, and standard deviation (SD) were used to present sociodemographic characteristics of the study participants.

\section{RESULTS}

A total of 384 patients were included in the study considering inclusion and exclusion criteria. Out of total 384 patients, $249(65 \%)$ were male and 135 (35\%) were female. This study shows male predominance. Gender-wise distribution is summarized in Fig. 1.

\section{Age-wise distribution of patients}

In this study, age ranged from 21 to 84 years. The mean age of the population was 58.28 (SD: 13.12). The majority of the participants were in the age group $>60$ years $(50 \%)$ of age. The age-wise distribution of patients is summarized in Fig. 2.

\section{Sociodemographic characteristics of the study participants}

Sociodemographic characteristics of the study participants were also analyzed. The relevant data are presented in Table 1.

\section{Distribution based on comorbidities}

Almost all the patients enrolled in the study had at least more than 1 comorbid condition. Hypertension (HTN) (34.10\%) is the most common comorbid condition which is followed by diabetes mellitus (DM) (20.30\%), anemia (13.30\%), and cardiovascular disorders (8.05\%).

The distribution of comorbidities in CKD patients is enumerated in Fig. 3.

\section{Medication usage pattern}

A total of 384 prescriptions were scrutinized with a total of 3634 drugs, out of which drugs acting on the cardiovascular system were the

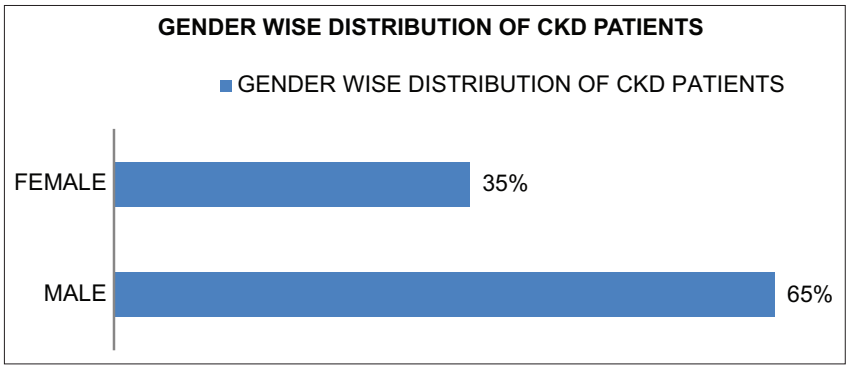

Fig. 1: Gender-wise distribution

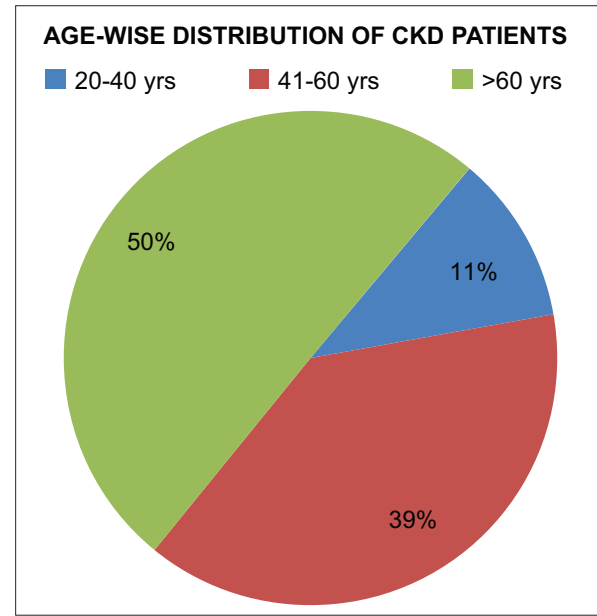

Fig. 2: Age-wise distribution

Table 1: Sociodemographic characteristics of the study participants

\begin{tabular}{|c|c|c|c|}
\hline Variables & Categories & $\begin{array}{l}\text { Frequency } \\
\text { (n) }\end{array}$ & Percentage \\
\hline & 20-40 years & 42 & 11 \\
\hline \multirow[t]{2}{*}{ Age (years) } & $41-60$ years & 150 & 39 \\
\hline & $>60$ years & 192 & 50 \\
\hline \multirow[t]{2}{*}{ Sex } & Male & 250 & 65 \\
\hline & Female & 134 & 35 \\
\hline \multirow[t]{2}{*}{ Marital status } & Married & 263 & 68.50 \\
\hline & Single & 121 & 31.50 \\
\hline \multirow[t]{4}{*}{ Education status } & Illiterate & 44 & 11.50 \\
\hline & Primary & 106 & 27.50 \\
\hline & Secondary & 130 & 34 \\
\hline & Higher & 104 & 27 \\
\hline \multirow{2}{*}{ Residence } & Urban & 246 & 64 \\
\hline & Rural & 138 & 36 \\
\hline \multirow[t]{5}{*}{ Occupation } & Retired & 119 & 31 \\
\hline & Private employee & 77 & 20 \\
\hline & Government employee & 31 & 8 \\
\hline & Business & 36 & 9.50 \\
\hline & Others & 121 & 31.50 \\
\hline \multirow[t]{2}{*}{ Social history } & Non-smokers & 275 & 71.50 \\
\hline & Smokers & 109 & 28.50 \\
\hline \multirow[t]{4}{*}{ Monthly income } & Low & 29 & 7.50 \\
\hline & Average & 59 & 15.50 \\
\hline & Above average & 94 & 24.50 \\
\hline & High & 202 & 52.50 \\
\hline \multirow[t]{3}{*}{ Duration of HTN } & $<5$ years & 111 & 29 \\
\hline & 5-15 years & 167 & 43.50 \\
\hline & Above 15 years & 106 & 27.50 \\
\hline
\end{tabular}

HTN: Hypertension.

most prescribed drugs (1322 drugs, 36.37\%) followed by vitamins and minerals (548 drugs, $15.07 \%$ ), hematinics (426 drugs, $11.72 \%$ ), and gastrointestinal drugs (334 drugs, 9.19\%), whereas acid-base disorder 


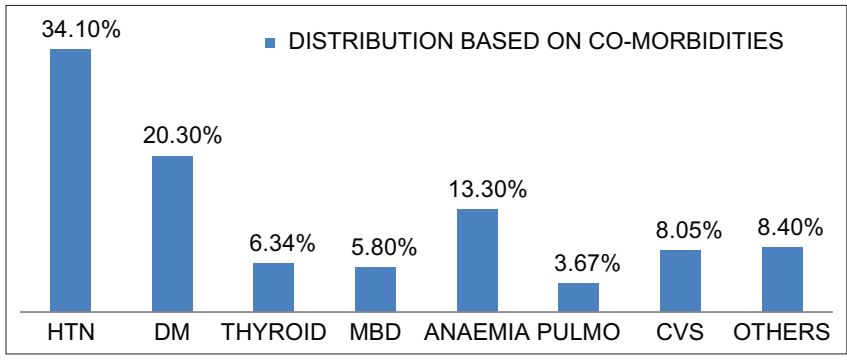

Fig. 3: Distribution based on comorbidities

drugs were least prescribed (30 drugs, $0.82 \%$ ). The most commonly prescribed combination therapy was antiplatelets + hypolipidemics (42 drugs, 36.20\%). A complete summary of the medication usage pattern among study participants is depicted in Table 2.

\section{WHO core drug use indicator}

In this current study, medication usage pattern was analyzed using the WHO core drug use indicators. A total of 3634 medicines were prescribed. Therefore, the average number of drugs per prescription was found to be 9.08 considering the total number of prescriptions. The percentage of drugs prescribed by generic name was $15.57 \%$. The percentage of encounters with antibiotics was $25 \%$, whereas percentage of encounters with injections was $86 \%$. The percentage of drugs prescribed from the essential drug list or formulary was found to be $26.36 \%$. A brief description of the WHO prescribing indicators is summarized in Table 3.

\section{DISCUSSION}

In this present study, out of 384 CKD patients, $65 \%$ were male whereas only $35 \%$ were female. This shows male predominance over females. Similar reports were published by various other authors. Shastry et al. [5] and Abhisek et al. [6] reported 75\% and 71.3\% of male dominance over the female.

This suggests that males are more prone to CKD when compared to females. This is mere because of different hormonal environments [7]. In this present study, the majority of the participants were in the age group $>60$ years $(50 \%)$ of age. A similar observation where the majority of participants were the elderly in the age group above 60 years (54\%) was made by Monika et al. [8].

The existence of several comorbid conditions leads to the requirement of multiple drug therapy to treat the underlying condition. The average number of drugs per prescription was found to be 9.08 considering the total number of prescriptions. Chakraborty et al. [9] and Al-Ramahi [10] reported that3almost similar results with an average number of drugs per prescription were 10 and 9.38, respectively.

Our study revealed that the percentage of drugs prescribed by generic name was found to be $15.57 \%$. Similar studies were conducted by Shrestha and Dixit and Shastry et al. where the percentage of drugs prescribed by generic name was $16.94 \%$ and $8.7 \%$, respectively [5,11]. Whereas, Ahlawat et al. and Bajait et al. reported none of the drugs prescribed with the generic name $[12,13]$. This revealed that prescribing with brand names remains a common practice in major parts of the world. Therefore, there is a need to encourage prescription writing by generic name to promote rational drug use.

This study revealed that the percentage of encounters with injections was $86 \%$. Similar results were reported by Shrestha and Dixit which were $71 \%$ of encounters with injections [11]. Prescribing a large number of injections in CKD patients is normal due to the presence of
Table 2: Medication usage pattern in CKD patients

\begin{tabular}{|c|c|c|}
\hline Drug class & Frequency & Percentage \\
\hline \multicolumn{3}{|c|}{ Cardiovascular drugs (n=1322, 36.37\%) } \\
\hline Calcium channel blockers & 250 & 18.91 \\
\hline Diuretics & 168 & 12.7 \\
\hline Centrally acting alpha agonist & 90 & 6.80 \\
\hline Beta-blockers & 194 & 14.67 \\
\hline Alpha-blockers & 122 & 9.22 \\
\hline Anticoagulants and ant platelets & 206 & 15.58 \\
\hline Hypolipidemics & 114 & 8.62 \\
\hline Vasodilators & 16 & 1.21 \\
\hline RAAS inhibitors & 74 & 5.59 \\
\hline Nitrates & 40 & 3.02 \\
\hline Others & 48 & 3.63 \\
\hline \multicolumn{3}{|l|}{ Hematinics ( $n=426,11.72 \%)$} \\
\hline Epoetin alpha & 204 & 47.88 \\
\hline IV iron sucrose & 144 & 33.80 \\
\hline Darbepoetin & 34 & 7.98 \\
\hline Oral elemental iron & 18 & 4.22 \\
\hline Folate & 26 & 6.10 \\
\hline \multicolumn{3}{|l|}{ Antidiabetic drugs ( $\mathrm{n}=186,5.11 \%$ ) } \\
\hline Insulin & 114 & 61.29 \\
\hline Oral hypoglycemic agents & 72 & 38.70 \\
\hline \multicolumn{3}{|c|}{ Vitamins and minerals ( $\mathrm{n}=548,15.07 \%)$} \\
\hline Calcium carbonate+Vitamin D3 & 156 & 28.46 \\
\hline Vitamin D3 derivatives & 92 & 16.78 \\
\hline Vitamin B complex & 94 & 17.15 \\
\hline Others & 206 & 37.59 \\
\hline \multicolumn{3}{|c|}{ Gastrointestinal drugs (n=334, 9.19\%) } \\
\hline Proton-pump inhibitors & 200 & 59.88 \\
\hline Dopamine antagonist & 10 & 2.99 \\
\hline $\mathrm{H} 2$ blockers & 18 & 5.38 \\
\hline Others & 106 & 31.73 \\
\hline \multicolumn{3}{|c|}{ Acid-base disorder drugs $(\mathrm{n}=30,0.82 \%)$} \\
\hline Sodium bicarbonate & 14 & 46.66 \\
\hline Febuxostat & 16 & 53.33 \\
\hline \multicolumn{3}{|l|}{ Phosphate binders ( $\mathrm{n}=92,2.53 \%)$} \\
\hline Calcium acetate & 6 & 6.52 \\
\hline Sevelamer & 86 & 93.47 \\
\hline \multicolumn{3}{|l|}{ Antibiotics ( $\mathrm{n}=130,3.57 \%)$} \\
\hline Cephalosporins & 52 & 40 \\
\hline Fluoroquinolones & 12 & 9.23 \\
\hline Aminoglycosides & 10 & 7.69 \\
\hline Penicillins & 6 & 4.61 \\
\hline Tetracyclines & 6 & 4.61 \\
\hline Carbepenems & 4 & 3.07 \\
\hline Others & 40 & 30.76 \\
\hline \multicolumn{3}{|l|}{ Analgesics ( $\mathrm{n}=84,2.31 \%)$} \\
\hline Acetaminophen+Tramadol & 22 & 26.19 \\
\hline Paracetamol & 38 & 45.23 \\
\hline Diclofenac & 8 & 9.52 \\
\hline Others & 16 & 19.04 \\
\hline \multicolumn{3}{|l|}{ Thyroid medications (n=62, 1.70\%) } \\
\hline Levothyroxine & 62 & 100 \\
\hline \multicolumn{3}{|c|}{ Drugs acting on nervous system ( $\mathrm{n}=96,2.64 \%)$} \\
\hline CNS drugs & 96 & 100 \\
\hline \multicolumn{3}{|l|}{ Miscellaneous drugs ( $\mathrm{n}=208,5.72 \%)$} \\
\hline Others & 208 & 100 \\
\hline \multicolumn{3}{|l|}{ Combination therapy ( $\mathrm{n}=116,3.19 \%)$} \\
\hline Antiplatelets+Hypolipidemics & 42 & 36.20 \\
\hline Vasodilators+Nitrates & 40 & 34.48 \\
\hline Calcium channel & 14 & 12.06 \\
\hline \multicolumn{3}{|l|}{ blockers+Beta-blockers } \\
\hline ARBs+Diuretics & 4 & 3.44 \\
\hline PPI+Dopamine blockers & 16 & 13.79 \\
\hline
\end{tabular}

ARBs: Angiotensin receptor blockers, PPI: Proton-pump inhibitors,

RAAS: Renin-angiotensin-aldosterone system, RASI:

Renin-angiotensin-aldosterone system inhibitor, CNS: Central nervous system.

comorbid conditions such as anemia and DM where parenteral use of erythropoietin and insulin is required for management. 
Table 3: WHO core drug indicator

\begin{tabular}{ll}
\hline Indicators & Data \\
\hline Prescribing indicators & \\
Average number of drugs per prescription & 9.08 \\
Percentage of drugs prescribed by generic name & $15.57 \%$ \\
Percentage of encounters with an antibiotics & $25 \%$ \\
Percentage of encounters with injections & $86 \%$ \\
Percentage of drugs prescribed from essential drug list & $26.36 \%$ \\
or formulary & \\
\hline
\end{tabular}

In our study, the percentage of encounters with antibiotics was $25 \%$. Our study results lie within the standard range (20.0-26.8\%) which is considered to be ideal [14]. Whereas other studies show a slightly higher range such as the study conducted by Shrestha and Dixit and Ulhas and Rataboli who reported $64.1 \%$ and $31.8 \%$ of encounters with antibiotics, respectively $[11,15]$.

In this current study, the percentage of drugs prescribed from the WHO essential drug list was found to be $26.36 \%$. Similar studies were conducted by Ahlawat et al. and Sindhura et al. who showed 19\% and $36.1 \%$ of drugs prescribed from the WHO essential drug list, respectively $[12,16]$.

In this study, cardiovascular drugs were the most prescribed drugs (661 drugs, 36.37\%) followed by vitamins and minerals $(n=274$, $15.07 \%)$ and hematinics $(n=213,11.72 \%)$. Whereas, a study conducted by Monika et al. who reported that cardiovascular drugs (16.48\%) are most frequently prescribed followed by gastrointestinal tract drugs $(14.07 \%)$ and nutritional supplements $(10.88 \%)$ [8]. Since the majority of the population suffers from the comorbid condition of HTN, cardiovascular drugs are mostly required for their management.

Among the cardiovascular drugs, calcium channel blockers (CCBs) were most commonly prescribed (18.91\%) in our study. Similar results were reported by Shastry et al. [5], Bailie et al. [17], Dasari et al. [18], and Tadvi and Hussain [19] where CCBs were most commonly prescribed constituting $78.05 \%, 27.6 \%, 60.5 \%$, and $52 \%$, respectively. Where as studies conducted by Chakraborty et al. [9], Ahlawat et al. [12], and Bajait et al. [13] constituting 9.29\%, 54\%, 9.50\% respectively followed by CCBs. In our study, nearly $80.05 \%$ of participants were at end-stage renal disease. Therefore, CCBs are being preferred over renin-angiotensin-aldosterone system inhibitors as this may aggravate hyperkalemia and also require dosage adjustment.

In our study, among phosphate binders (PBs), 93.47\% of sevelamer was prescribed while only $6.52 \%$ of calcium acetate was prescribed. A study conducted by Martins et al. who reported the high use of sevelamer (45.4\%) over other calcium-based PBs (26.5\%) [20]. In contrast to the studies conducted by Chakraborty et al. (11.02\%) [9] and Bajait et al. (9.97\%) [13] reported higher use of calcium-based PBs when compared to sevelamer due to high cost.

Sevelamer, a newer non-calcium, non-aluminum binder, is used more frequently to avoid soft-tissue calcification which is caused by calciumbased PBs such as calcium acetate and calcium carbonate. Moreover, sevelamer is associated with a reduction of coronary and aortic calcification [13]. A recent meta-analysis reported that non-calciumbased PBs associated with a $22 \%$ reduction in all-cause mortality compared to calcium-based PBs in CKD patients [21].

\section{CONCLUSION}

Assessment of medication usage patterns using the WHO core indicators in CKD patients helps to reinforce the current hospital guidelines for the optimal usage of medications. Due to the existence of comorbid conditions in CKD patients, polypharmacy remains the common practice in the clinical setting. Therefore, the likelihood for drug interactions and adverse outcomes are very common. The introduction of a clinical pharmacist along with a multidisciplinary team provides intensive care to the patients and helps to improve the clinical outcome. There is a need to encourage prescription writing in generic names to eliminate medication errors and need to enhance the medication use from the WHO essential drug list for the easy access to the cost-effective medication.

Further sophisticated studies with special emphasis on drug interaction, adverse events, pharmacoeconomics, and assessment tools for early detection of CKD need to be carried out.

\section{AUTHORS' CONTRIBUTION}

Concept, design, data analysis, and manuscript writing of the study were done by the first author. The second and third authors helped in guiding. The fourth author helped in data collection.

\section{CONFLICTS OF INTEREST}

There are no conflicts of interest.

\section{AUTHORS' FUNDING}

Self.

\section{REFERENCES}

1. Steven Baldridge; Why Kidney Health is Vital to Your Overall Wellbeing; 2019. Available form: https://www.uhhospitals.org/Healthy-atUH/articles/2019/08/why-kidney-health-is-vital-to-your-overall-wellbeing

2. Kamath L, Hema NG, Himamani S. A study of drug utilization pattern in patients of chronic kidney disease at a tertiary care hospital. Int J Basic Clin Pharmacol 2019;8:170.

3. Bindroo S, Rodriguez BS, Challa HJ. Renal Failure. Treasure Island, FL: StatPearls Publishing; 2021.

4. Carney EF. The impact of chronic kidney disease on global health. Nat Rev Nephrol 2020;16:251.

5. Shastry CS, Al-Jabri MM, Chand S. Assessment of drug utilization pattern in chronic kidney disease patients in a tertiary care hospital based on WHO core drug use indicators. J Global Pharma Technol 2019;11:1-9.

6. Abhisek PA, Panda RK, Samal R, Mohapatra N, Mohanty S. Drug utilization pattern and adverse events in patients with chronic kidney disease undergoing maintenance haemodialysis at a tertiary care hospital of Odisha. J Clin Diagn Res 2017;11: FC11-6.

7. Carrero JJ, Hecking M, Chesnaye NC, Jager KJ. Sex and gender disparities in the epidemiology and outcomes of chronic kidney disease. Nat Rev Nephrol 2018;14:151-14.

8. Monika KA, Charitha KS, Reddy MR, Vaishnavi K, Prudhivi R, Jyothi. A study on drug utilization review and potential drug-drug interactions in chronic kidney disease patients. Global J Med Res 2018;18:1-9. Available form: https://medicalresearchjournal.org/index.php/GJMR/ article/view/1582.

9. Chakraborty S, Ghosh S, Banerjea A, Raman De R, Hazra A, Mandal SK. Prescribing patterns of medicines in chronic kidney disease patients on maintenance hemodialysis. Indian J Pharmacol 2016;48:586-90.

10. Al-Ramahi R. Medication prescribing patterns among chronic kidney disease patients in a hospital in Malaysia. Saudi J Kidney Dis Transpl 2012;23:403-8.

11. Shrestha B, Dixit SM. Assessment of drug use pattern using WHO prescribing indicators. J Nepal Health Res Council 2018;16:279-84.

12. Ahlawat R, Cruz SD, Tiwari P. Drug utilization pattern in chronic kidney disease patients at a tertiary care public teaching hospital: Evidence from a cross-sectional study. J Pharma Care Health Sys 2015;3:149.

13. Bajait C, Pimpalkhute S, Sontakke SD, Jaiswal KM, Dawri AV. Prescribing pattern of medicines in chronic kidney disease with emphasis on phosphate binders. Indian J Pharmacol 2014;46:35-9.

14. Isah AO, Ross-Degnan D, Quick J, Laing R, Mabadeje AF. The Development of Standard Values for the WHO Drug Use Prescribing Indicators. ICUM/EDM/WHO. Available from: https:/www.ajol.info/ index.php/wajpdr/article/view/14718. [Last accessed on 2014 Aug 10].

15. Ulhas KC, Rataboli PV. A study of drug prescribing pattern using WHO prescribing indicators in the state of Goa, India. Int J Basic Clin Pharmacol 2014;3:1057-61.

16. Sindhura P, Balaiah S, Grace BS, Charan TK. Assessment of drug 
prescribing pattern in patients of CKD along with CVD in tertiary care hospital. Int J Pharm Sci Rev Res 2018;49:33-8.

17. Bailie GR, Eisele G, Liu L, Roys E, Kiser M, Finkelstein F, et al. Pattern of medication use in the RRI-CKD study: Focus on medications with cardiovascular effects. Nephrol Dial Transplant 2005;20:1110-5.

18. Dasari P, Venkateswarlu K, Venisetty RK. Management of comorbidities in chronic kidney disease: A prospective observational study. Int J Pharm Pharm Sci 2012;6:363-7.

19. Tadvi N, Hussain S. Analysis of prescription pattern in patients on maintenance hemodialysis. Indian J Pharm Pharmacol 2020;7:125-9.

20. Martins MT, Da Silva LF, Márcia TS, Matos CM, Melo NA, Cardoso MF, et al. Prescription of phosphate binders and calcitriol for chronic hemodialysis patients. Rev Assoc Med Bras 2009;55:70-4.

21. Jamal SA, Vandermeer B, Raggi P, Mendelssohn DC, Chatterley T, Dorgan $\mathrm{M}$, et al. Effect of calcium-based versus non-calcium-based phosphate binders on mortality in patients with chronic kidney disease: An updated systematic review and meta-analysis. Lancet 2013;382:1268-77. 